\title{
Benefits of monitoring patients with mobile cardiac telemetry (MCT) compared with the Event or Holter monitors
}

This article was published in the following Dove Press journal:

Medical Devices: Evidence and Research

6 December 2013

Number of times this article has been viewed

\author{
Jean-Patrick Tsang \\ Shunmugam Mohan \\ Bayser Consulting, Skokie, IL, USA
}

\begin{abstract}
Introduction: This research is meant to establish if a patient monitored with mobile cardiac telemetry (MCT) sees different outcomes regarding diagnostic yield of arrhythmia, therapeutic management through the use of antiarrhythmic drugs, and cardiovascular costs incurred in the hospital setting when compared with more traditional monitoring devices, such as the Holter or the Event monitor.
\end{abstract}

Materials and methods: We conducted a retrospective analysis spanning 57 months of claims data from January 2007 to September 2011 pertaining to 200,000+ patients, of whom 14,000 used MCT only, 54,000 an Event monitor only, and 163,000 a Holter monitor only. Those claims came from the Truven database, an employer database that counts 2.8 million cardiovascular patients from an insured population of about 10 million members. We employed a pair-wise pre/post test-control methodology, and ensured that control patients were similar to test patients along the following dimensions: age, geographic location, type of cardiovascular diagnosis both in the inpatient and outpatient settings, and the cardiovascular drug class the patient uses.

Results: First, the diagnostic yield of patients monitored with MCT is $61 \%$, that is significantly higher than that of patients that use the Event monitor (23\%) or the Holter monitor (24\%). Second, patients naive to antiarrhythmic drugs initiate drug therapy after monitoring at the following rates: $61 \%$ for patients that use MCT compared with $39 \%$ for patients that use the Event and $43 \%$ for patients that use the Holter. Third, there are very significant inpatient cardiovascular savings (in the tens of thousands of dollars) for patients that undergo ablation, coronary artery bypass graft $(\mathrm{CABG})$ and valve septa. Savings are more modest but nonetheless significant when it comes to the heart/pericardium procedure.

Conclusion: Given the superior outcome of MCT regarding both patient care and hospital savings, hospitals only stand to gain by enforcing protocols that favor the MCT system over the Event or the Holter monitor.

Keywords: mobile cardiac telemetry, Holter monitor, Event monitor, diagnostic yield, arrhythmia

\section{Introduction}

The mobile cardiac telemetry (MCT) system is a small sensor and monitor that patients wear as they go about their daily lives. Whenever cardiac events occur, MCT instantaneously transmits the data to a center for analysis and response, which in turn sends a report along with graphs and trends to the patient's physician for diagnosis and therapy management. ${ }^{1,2}$ Given the convenience of the device and its ability to identify arrhythmia cases that other devices miss (thanks to its superior ability to analyze the morphology of the electrocardiogram [EKG/ECG]), the expectation was immediate adoption. ${ }^{3}$
Correspondence: Jean-Patrick Tsang Bayser Consulting, 4709 Golf Road Suite 803 , Skokie, IL 60076, USA

Tel +l 8479201000

Fax + I 8476798285

Email bayser@bayser.com 
This is not what happened though. Instead, patients continued to use the Holter and Event monitors. Both are small portable devices that the patient wears. The difference between the Holter and the Event is that the Holter records the patient's EKG for 24-48 hours, while the Event records the EKG at certain times only and typically for a 30-day period.

Understandably, several payers responded by asking for hard evidence that indicates that the use of MCT indeed leads to better outcomes before they are to adopt MCT. Several studies were undertaken to explain from a clinical standpoint how MCT leads to better outcomes. Unfortunately, those studies ran into challenges, and could not convincingly demonstrate causality. ${ }^{4-7}$

Is MCT not widely adopted just because studies fail to prove its effectiveness? ${ }^{8}$ To elucidate the matter, we decided to conduct an observational study that differed from previous ones in one respect. Instead of focusing on explaining causality, this study set out to establish if patients that use MCT indeed have better outcomes. The rationale that links the two was deliberately regarded as out of scope, otherwise this study would be fraught with the same issues that overwhelmed the previous ones.

\section{Materials and methods}

We conducted three analyses to assess the impact of usage of MCT on 1) diagnostic yield of arrhythmia, 2) management of arrhythmia through the use of antiarrhythmic drugs, and 3) cardiovascular costs incurred in the inpatient setting. ${ }^{9-11}$ Table 1 shows the profile of the patients that use MCT, Event, and Holter monitors.

Table I Demographic information of patients using MCT, Event, and Holter monitors

\begin{tabular}{llllll}
\hline Sex: age & Midwest & Northeast & South & West & Total \\
\hline $\begin{array}{l}\text { Females: } \\
<40 \text { years }\end{array}$ & $0.7 \%$ & $0.4 \%$ & $1.1 \%$ & $0.4 \%$ & $2.5 \%$ \\
$\begin{array}{l}\text { Males: } \\
<40 \text { years }\end{array}$ & $2.2 \%$ & $1.1 \%$ & $4.4 \%$ & $1.2 \%$ & $8.9 \%$ \\
$\begin{array}{l}\text { Females: } \\
40-65 \text { years }\end{array}$ & $4.6 \%$ & $2.1 \%$ & $7.3 \%$ & $2.2 \%$ & $16.1 \%$ \\
$\begin{array}{l}\text { Males: } \\
40-65 \text { years }\end{array}$ & $5.9 \%$ & $2.4 \%$ & $10.7 \%$ & $3.0 \%$ & $22.0 \%$ \\
$\begin{array}{l}\text { Females: } \\
>65 \text { years }\end{array}$ & $10.9 \%$ & $2.9 \%$ & $7.3 \%$ & $3.8 \%$ & $24.9 \%$ \\
$\begin{array}{l}\text { Males: } \\
>65 \text { years }\end{array}$ & $11.0 \%$ & $2.9 \%$ & $7.7 \%$ & $3.9 \%$ & $25.6 \%$ \\
\begin{tabular}{l} 
Total \\
\hline Abrevil
\end{tabular} & $35.3 \%$ & $11.8 \%$ & $38.4 \%$ & $14.5 \%$ & $100 \%$ \\
\hline
\end{tabular}

Abbreviation: MCT, mobile cardiac telemetry.

\section{Analysis I: diagnostic yield}

In this analysis, the patient had to meet the following conditions:

1. used only one cardiac-monitoring device (MCT or Holter or Event monitor)

2. used the cardiac-monitoring device 12 months after the start of the database and 12 months before the end of the database

3. had no arrhythmic International Classification of Diseases (ICD-9) diagnosis code prior to using the cardiacmonitoring device.

We then used for each of the three populations: 1) number of patients in the population (none had an arrhythmia diagnosis prior to the use of the cardiac-monitoring device), and 2) number of patients within the previous group that had an arrhythmic ICD-9 diagnosis code after use of the cardiac-monitoring device. We then computed the diagnostic yield as the ratio of 2 to 1 .

\section{Analysis 2: antiarrhythmic drug management}

This analysis is similar to the previous one. The patient had to meet the following conditions:

1. used only one cardiac-monitoring device (MCT or Holter or Event monitor)

2. used the cardiac-monitoring device 12 months after the start of the database and 12 months before the end of the database

3. had no arrhythmic diagnosis ICD-9 code prior to the cardiac monitoring device

4. [new] used no antiarrhythmic drug prior to the cardiacmonitoring device.

We then used for each of the three populations: 1) number of patients in the population (none had an arrhythmia diagnosis or took an antiarrhythmic drug prior to the cardiacmonitoring device), and 2) number of patients within the previous group that took an antiarrhythmic drug after the use of the cardiac-monitoring device. We then computed the antiarrhythmic drug usage as the ratio of 2 to 1 .

\section{Analysis 3: cost savings in the hospital setting}

The control patients had to meet the following conditions (there were two groups: one for the Holter and the other for the Event monitor):

1. used only one cardiac-monitoring device (Holter or Event monitor) and did so once 
2. used the Holter or Event monitor 12 months after the start of the database and 12 months before the end of the database.

For pairing to happen, both the test and control patients had to meet the following conditions:

1. were either younger or older than 65 years, to factor in Medicare

2. came from the same type of Medicaid state: Medicaidexpansion states (CT and MA), on-track Medicaid states (AZ, DE, ME, MN, NY, PA, WA WI, HI, DC), or Medicaid-challenged states (rest of the US), to factor in dual eligibles whose access to MCT was subject to Medicaid state rules

3. had the same diagnosis, as defined by the following eight diagnosis groups: acute coronary syndrome, stroke/ transient ischemic attack, heart failure, arrhythmia, coronary artery disease, peripheral artery disease, hypertension, and other cardiovascular conditions

4. used the same $\operatorname{drug}(\mathrm{s})$, as defined by the following four drug classes: anti-platelet, antiarrhythmic, anticoagulant, and antihyperlipidemic

5. used inpatient cardiovascular resources to comparable levels before the cardiac monitor.

We then conducted the following measurements. First, we compared MCT patients with paired-up Holter patients, and second with paired-up Event monitor patients. In both cases, we defined the following: 1) increase in cardiovascular expenses of MCT patients as the difference in cardiovascular costs incurred in the 12 months that followed MCT (post-period) and the cardiovascular costs incurred in the 12 months before MCT (pre-period), 2) the corresponding per-patient difference of the matched control patients to the test patient, 3) the savings due to MCT compared with the other cardiac monitor as the difference between 1 and 2 .

We chose a pair-wise test-control approach to allow for the fact that MCT patients may not be a homogeneous group and large differences between patients may occur. Also, we paired each test not with one but with five controls to minimize the vagaries of pairing.

We also conducted additional analyses to refute the following objections:

1. savings are artificially low because of the way the pairing is done; indeed, costs incurred for the MCT patient are low because the patient is from a low consumer price index (CPI) geography, while the costs incurred for the other cardiac monitoring device are high because the patient is from a high CPI geography
Table 2 Patients diagnosed with arrhythmia when using MCT, Event, and Holter monitors

\begin{tabular}{lllll}
\hline & $\mathbf{n}$ & Diagnosed & Difference & $P$-value \\
\hline MCT & 5,129 & $61.3 \%$ & & \\
Event & 24,023 & $23.0 \%$ & $36 \%$ & 0.0006 \\
Holter & 57,143 & $24.2 \%$ & $35 \%$ & 0.0006 \\
\hline
\end{tabular}

Abbreviation: MCT, mobile cardiac telemetry.

2. MCT does not lead to any savings, what is happening is simply that costs are still incurred but delayed until the second year following MCT, which the test-control approach fails to pick up on as its postperiod ends before the significant costs are incurred.

In the first case, we reran the analysis by imposing the condition that both test and control patients be from the same geography. The results barely changed, knocking out the CPI argument. In the second case, we reran the analysis, extending the postperiod to 24 months. Once again, the results barely changed, undercutting the basis for the delay argument.

\section{Results}

\section{Analysis I: diagnostic yield}

Table 2 indicates that $61 \%$ of patients that use MCT are diagnosed with arrhythmia subsequent to the use of the monitor. This is to be compared with $23 \%$ for those that use an Event monitor and 24\% for those that use a Holter monitor. A $Z$-test for the difference between two sample proportions (MCT versus Event) revealed that the proportion of patients diagnosed with arrhythmia was $36 \%$ higher when the monitor was MCT instead of an Event $(P=0.0006)$. The result was virtually unchanged (35\% instead of $36 \%)$ when MCT was compared with the Holter $(P=0.0006)$.

\section{Analysis 2: antiarrhythmic drug management}

Table 3 indicates that $61 \%$ of patients that use MCT are diagnosed with arrhythmia and treated for the first time with an antiarrhythmic drug subsequent to the use of the monitor. This is to be compared with 39\% for those that use an Event monitor

Table 3 Patients treated with antiarrhythmic drugs when using MCT, Event, and Holter monitors

\begin{tabular}{lllll}
\hline & $\mathbf{n}$ & Treated & Difference & P-value \\
\hline MCT & 5,005 & $61.1 \%$ & & \\
Event & 22,078 & $39.0 \%$ & $20 \%$ & 0.0033 \\
Holter & 52,097 & $43.0 \%$ & $16 \%$ & 0.0018 \\
\hline
\end{tabular}

Abbreviation: MCT, mobile cardiac telemetry. 
Table 4 Savings when using MCT: ablation, CABG, heart/ pericardium, and valve/septa procedures

\begin{tabular}{|c|c|c|c|c|c|c|}
\hline & \multicolumn{3}{|c|}{ MCT vs Event } & \multicolumn{3}{|c|}{ MCT vs Holter } \\
\hline & $\begin{array}{l}\text { Savings } \\
\text { (US\$) }\end{array}$ & $\mathbf{n}$ & $P$-value & $\begin{array}{l}\text { Savings } \\
\text { (US\$) }\end{array}$ & $\mathbf{n}$ & $P$-value \\
\hline Ablation & 35,114 & 54 & $<0.0001$ & 36,115 & 45 & $<0.0001$ \\
\hline CABG & & & & 41,700 & 32 & 0.0003 \\
\hline $\begin{array}{l}\text { Heart/ } \\
\text { pericardium }\end{array}$ & $|7| 3 \mid$, & 43 & $0.028 I$ & 8,606 & 54 & 0.0003 \\
\hline Valve/septa & 58,362 & 35 & 0.0422 & 55,390 & 46 & 0.0003 \\
\hline
\end{tabular}

Abbreviations: MCT, mobile cardiac telemetry; CABG, coronary artery bypass graft; vs, versus.

and $43 \%$ for those that use a Holter monitor. A Z-test for the difference between two sample proportions (MCT versus Event monitor) revealed that the proportion of patients diagnosed with arrhythmia and treated for the first time with an antiarrhythmic drug was 20\% higher when the monitor was MCT instead of an Event $(P=0.0033)$. The difference dropped just slightly to $16 \%$ when MCT was compared with the Holter $(P=0.0018)$.

\section{Analysis 3: cost savings in the hospital setting}

Table 4 is a summary of the cardiovascular savings (in US\$) incurred in the hospital when the patient used the MCT instead of the Event or Holter monitor when undergoing different types of surgeries. Those savings were registered in the 12 months that followed the use of the cardiac-monitoring device. All the sample sizes were larger than 30 and the $P$-value less than 0.05 . The only cases not reported were for patients undergoing a coronary artery bypass graft (CABG) using MCT instead of an Event monitor, and that was because the sample size was only twelve (although savings were very significant US\$150,000, with a $P$-value of 0.0299).

Let us take a closer look at each of the four procedures discussed in Table 4 . In the case of ablation, MCT led to savings of US\$35,114 $(P<0.0001)$ in inpatient cardiovascular costs over the 12 months that followed the use of the

Table 5 Savings (US\$) when using MCT - ablation

\begin{tabular}{|c|c|c|c|c|c|}
\hline & Device & Pre- & Post- & Difference & $P$-value \\
\hline \multicolumn{6}{|c|}{ MCT vs Event $(n=54)$} \\
\hline Test & MCT & 16,132 & 10,376 & $(5,756)$ & \\
\hline Control & Event & 6,043 & 35,400 & 29,358 & \\
\hline Impact & & & & $(35,114)$ & $<0.0001$ \\
\hline \multicolumn{6}{|c|}{ MCT vs Holter $(n=45)$} \\
\hline Test & MCT & 17,996 & 8,485 & $(9,5 I I)$ & \\
\hline Control & Holter & 2,759 & 29,362 & 26,604 & \\
\hline Impact & & & & $(36,1 \mid 5)$ & $<0.0001$ \\
\hline
\end{tabular}

Abbreviations: MCT, mobile cardiac telemetry; vs, versus.
Table 6 Savings (US\$) when using MCT - CABG

\begin{tabular}{|c|c|c|c|c|c|}
\hline & \multicolumn{5}{|c|}{ MCT vs Holter $(n=32)$} \\
\hline & Device & Pre- & Post- & Difference & $P$-value \\
\hline Test & МСT & 28,508 & 17,820 & $(10,688)$ & \\
\hline Control & Holter & 8,960 & 39,972 & 31,012 & \\
\hline Impact & & & & $(4 I, 700)$ & 0.0003 \\
\hline
\end{tabular}

device compared with the Event monitor and US\$36,115 $(P<0.0001)$ compared with the Holter. (Table 5).

In the case of $\mathrm{CABG}$ procedures, MCT led to savings of US\$41,700 ( $P=0.0003)$ in inpatient cardiovascular costs per patient over the 12 months that followed the use of the device compared with the Holter. (Table 6).

In the case of heart/pericardium procedures, MCT led to savings of US $\$ 17,131(P=0.0281)$ in inpatient cardiovascular costs per patient over the 12 months that followed the use of the device compared with the Event monitor and US\$8,606 $(P=0.0003)$ compared with the Holter. (Table 7).

In the case of valve/septa procedures, MCT led to savings of US\$58,362 ( $P=0.0422)$ in inpatient cardiovascular costs per patient over the 12 months that followed the use of the device compared with the Event monitor and US $\$ 55,390$ ( $P=0.0003$ ) compared with the Holter (Table 8).

\section{Discussion}

While there certainly is a good rationale, albeit subtle, as to why use of MCT leads to better patient outcomes, offering an explanation will displace the focus of the discussion to a more controversial area, resulting in the expectation that consensus needs to be reached before any action is to be taken. That is the trap to avoid, so we will refrain from offering any explanation.

Faced with the evidence uncovered here, why would a hospital still be better off not to adopt MCT? For one, it may

Table 7 Savings (US\$) when using MCT - heart/pericardium procedures

\begin{tabular}{|c|c|c|c|c|c|}
\hline & Device & Pre- & Post- & Difference & $P$-value \\
\hline \multicolumn{6}{|c|}{ MCT vs Event $(n=43)$} \\
\hline Test & MCT & 11,227 & 15,470 & 4,243 & \\
\hline Control & Event & 2,961 & 24,334 & 21,374 & \\
\hline Impact & & & & $(|7| 3 \mid)$, & 0.0281 \\
\hline \multicolumn{6}{|c|}{ MCT vs Holter $(n=54)$} \\
\hline Test & $\mathrm{MCT}$ & 6,010 & 8,065 & 2,055 & \\
\hline Control & Holter & 1,016 & 11,677 & $|0,66|$ & \\
\hline Impact & & & & $(8,606)$ & 0.0003 \\
\hline
\end{tabular}

Abbreviations: MCT, mobile cardiac telemetry; vs, versus. 
Table 8 Savings (US\$) when using MCT - valve/septa procedures

\begin{tabular}{|c|c|c|c|c|c|}
\hline & Device & Pre- & Post- & Difference & $P$-value \\
\hline \multicolumn{6}{|c|}{ MCT vs Event $(n=35)$} \\
\hline Test & MCT & 55,624 & 86,291 & 30,667 & \\
\hline Control & Event & 23,345 & 112,374 & 89,029 & \\
\hline Impact & & & & $(58,362)$ & 0.0422 \\
\hline \multicolumn{6}{|c|}{ MCT vs Holter $(n=46)$} \\
\hline Test & MCT & 30,429 & 42,436 & 12,007 & \\
\hline Control & Holter & 10,912 & 78,308 & 67,397 & \\
\hline Impact & & & & $(55,390)$ & 0.0003 \\
\hline
\end{tabular}

Abbreviations: MCT, mobile cardiac telemetry; vs, versus.

be the case that MCT generates a significant number of false positives, which the Holter or Event monitors do not, leading the hospital to incur unnecessary treatment costs. But that concern has no merit, as MCT uses a morphology-based diagnosis algorithm that only reports problems that are present in the EKG. Besides, the costs of the MCT, Holter, and Event monitors are very comparable and very small in the larger scheme of things. For another, the hospital may not be convinced of the rationale that underpins the usage of MCT and better patient outcomes. But is that in the best interest of the patients?

\section{Conclusion}

Our findings can be summed up as follows: use of MCT instead of an Event or a Holter monitor leads to better outcomes regarding diagnostic yield, management of arrhythmia through the use of antiarrhythmic drugs, and cost savings in the hospital for ablation, CABG, heart/pericardium, and valve/septa procedures.

In the unlikely event that MCT does not offer the benefits discussed, adopting MCT in lieu of Holter or Event monitors will not make the hospital worse off. But if, as we presented, MCT does offer the benefits discussed, then adopting MCT is clearly the superior choice. It is then clear that the optimal decision for the hospital is unambiguous: adopt MCT without any further delay.

\section{Acknowledgments}

We would like to thank Tony Likovich with Truven Healthcare for making this data available to us. We would also like to thank Joseph Capper and Michael Geldart with CardioNet for partially defraying the cost of this study.

\section{Disclosure}

The authors report no conflicts of interest in this work.

\section{References}

1. Joshi AK, Kowey PR, Prystowsky EN, et al. First experience with a Mobile Cardiac Outpatient Telemetry (MCOT) system for the diagnosis and management of cardiac arrhythmia. Am J Cardiol. 2005;95:878-881.

2. Rothman SA, Laughlin JC, Seltzer J, et al. The diagnosis of cardiac arrhythmias: a prospective multi-center randomized study comparing mobile cardiac outpatient telemetry versus standard loop event monitoring. J Cardiovasc Electrophysiol. 2007;18:1-7.

3. Salleh SH, Hussain HS, Swee TT, et al. Acoustic cardiac signals analysis: a Kalman filter-based approach. Int J Nanomedicine. 2012;7: 2873-2881.

4. Prystowsky EN. Assessment of rhythm and rate control in patients with atrial fibrillation. J Cardiovasc Electrophysiol. 2006;17 Suppl 2: S7-S10.

5. Rockx MA, Hoch JS, Klein GL, et al. Is ambulatory monitoring for "community-acquired" syncope economically attractive? A costeffectiveness analysis of a randomized trial of external loop recorders versus Holter monitoring. Am Heart J. 2005;150:1065-1075.

6. Padeletti L, Mascioli G, Perini AP, et al. Critical appraisal of cardiac implantable electronic devices: complications and management. Med Devices (Auckl). 2011;4:157-167.

7. Brüggenjürgen B, Israel CW, Klesius AA, Ezzat N, Willich SN. Health services research in heart failure patients treated with a remote monitoring device in Germany - a retrospective database analysis in evaluating resource use. J Med Econ. 2012;15(4):737-745

8. Reynolds TM. Targeting treatment using calculated cardiovascular disease risk: effective? A shot in the dark? Or is it time to change the paradigm? Int J Clin Pract. 2009;63:1785-1791.

9. Hoefman E, Van Weert HC, Reitsma JB, Koster RW, Bindels PJ. Diagnostic yield of patient-activated loop recorders for detecting heart rhythm abnormalities in general practice: a randomized clinical trial. Fam Pract. 2005;22:478-484.

10. Reiffel JA, Schwarzberg R, Murry M. Comparison of autotriggered memory loop recorders versus standard loop recorders versus 24-hour Holter monitors for arrhythmia detection. Am J Cardiol. 2005;95:1055-1059.

11. Allen LA, Smoyer Tomic KE, Wilson KL, Smith DM, Agodoa I. The inpatient experience and predictors of length of stay for patients hospitalized with systolic heart failure: comparison by commercial, Medicaid, and Medicare payer type. J Med Econ. 2013;16:43-54.
Medical Devices: Evidence and Research

\section{Publish your work in this journal}

Medical Devices: Evidence and Research is an international, peerreviewed, open access journal that focuses on the evidence, technology, research, and expert opinion supporting the use and application of medical devices in the diagnosis, treatment and management of clinical conditions and physiological processes. The identification of novel

\section{Dovepress}

devices and optimal use of existing devices which will lead to improved clinical outcomes and more effective patient management and safety is a key feature. The manuscript management system is completely online and includes a quick and fair peer-review system. Visit http://www. dovepress.com/testimonials.php to read real quotes from authors. 